\title{
RAZÃo ARGUMENTATIVA, PROCESSO ELETRÔNICO E ACELERAÇÃo: O TEMPO DA APRENDIZAGEM NO ENSINO JURÍDICO E SEUS EFEITOS NO BRASIL
}

Francisco Cardozo Oliveira ${ }^{1}$ Nancy Mahra de Medeiros Nicolas Oliveira ${ }^{2}$

\section{RESUMO}

O artigo trata da relação entre aprendizagem e realização da justiça mediada pela concepção de aceleração social. Afirma-se que a racionalidade argumentativa e o processo eletrônico alteram o tempo da aprendizagem no direito e de realização da justiça. A compressão do tempo reduz a experiência cognitiva e emocional necessária à consolidação do conhecimento. O processo eletrônico, embora reduza os tempos do processo, contribui para esvaziar a experiência de sentido da normatividade. Sustenta-se que a razão argumentativa busca uma saída para essa dupla perda da experiência, com o risco de assumir um caráter regressivo na tutela de direitos no Brasil.

PALAVRAS-CHAVE: racionalidade argumentativa; processo eletrônico; aceleração social; ensino jurídico; realização da justiça.

\section{ARGUMENTATIVE REASON, ELECTRONIC PROCESS AND ACCELERATION:}

THE TIME OF LEARNING IN LAW EDUCATION AND THEIR EFFECTS IN

BRAZIL

\section{ABSTRACT}

The article deals with the relation between learning and realization of justice mediated by the concept of social acceleration. It is argued that argumentative rationality and the electronic process alter the time of learning in the law and the realization of justice. Time compression reduces the cognitive and emotional experience needed to consolidate knowledge. The electronic process contributes to empty the experience of sense of the normativity. It is argued

\footnotetext{
${ }^{1}$ Professor de Direito Civil e de Fundamentos do Direito e do Estado. E-mail: xikocardozo@msn.com

${ }^{2}$ Professora de Direito Processual do Trabalho. E-mail: nancynicolas@hotmail.com
} 
that argumentative reason seek the way out of this double loss of experience, with the risk of assuming a regressive character in the protection of rights in Brazil.

KEYWORDS: argumentative rationality; electronic process; social acceleration; Law education; achievement of Justice.

\section{INTRODUÇÃO}

A análise trata do tempo da aprendizagem e seus efeitos no ensino jurídico no Brasil. A questão da temporalidade no processo de aprendizagem é examinada em duas perspectivas que funcionam como antecedentes lógicos da reflexão: a da razão argumentativa e seus efeitos na tutela de direitos; e a da cultura digital e o conhecimento jurídico, com seus reflexos no processo eletrônico. Em seguida, a análise trata de forma específica do tempo da aprendizagem confrontada com o tempo da justiça, no contexto de aceleração da vida na contemporaneidade pós-moderna.

Justifica-se a análise em dois aspectos; um mais amplo, relacionado ao modo como a aprendizagem no ensino jurídico produz efeitos na cultura jurídica e na pesquisa na área do direito; outro, mais específico, no modo como a aprendizagem no ensino jurídico repercute efeitos na alteração de paradigmas do conhecimento e nos fundamentos do direito. Neste segundo aspecto, a análise também se justifica em função do potencial de mudança social que o sistema jurídico possa engendrar na realidade brasileira de assimetrias marcantes.

Destas justificativas decorre o objetivo de uma análise da relação entre o tempo de aprendizagem e a formação jurídica, capaz de captar o sentido de justiça na dimensão das dificuldades verificadas na dinâmica de evolução social na realidade brasileira.

O problema a ser enfrentado diz respeito à indagação do modo como o tempo da aprendizagem e o da justiça podem ser influenciados pela razão argumentativa e pelo processo eletrônico, no contexto de aceleração da vida, tendo-se em conta a realidade pósmoderna e, de forma mais específica, a evolução da sociedade brasileira.

Para enfrentar o problema proposto, a análise se inicia tratando do modo como a razão argumentativa pode estabelecer a compreensão dos fatos e, consequentemente, da tutela de direitos; em seguida, avalia-se a relação entre cultura digital e processo eletrônico e seus efeitos no conhecimento jurídico; no final, a ênfase recai sobre o tempo da aprendizagem e o

CONPEDI LAW REVIEW | Braga - Portugal | v. 3 | n. 2 | p. 106 - 126 | JUL/DEZ. 2017 
da justiça mediante uma análise a partir da concepção de aceleração social formulada no desenvolvimento da teoria crítica.

A análise está apoiada em pesquisa bibliográfica. Adota-se uma metodologia crítica, em que o método não é dado a priori, nos termos de uma visão cartesiana, mas se desenvolve em paralelo à reflexão.

\section{RAZÃo ARGUMENTATIVA, COMPREENSÃo DOS FATOS E TUTELA DE DIREITOS}

A racionalidade argumentativa no direito ganhou maior relevância em face da virada hermenêutica que coloca ênfase na primazia do caso. De acordo com Castanheira Neves, uma visão jurisprudencialista do direito sustenta que a decisão judicial é resultado de uma opção, entre várias alternativas, que exige uma racionalidade prática argumentativa, direcionada para a solução de problemas concretos e que mobiliza referências culturais situadas no arranjo de uma comunidade histórica; diz ele que a argumentação busca uma racionalidade fundamentalmente processual ou procedimental, em que o enunciado normativo pode ser considerado válido ou verdadeiro se resultar de uma forma de procedimento do discurso racional (1993, p.36-81). A racionalidade argumentativa busca persuadir em busca do consenso sobre o alcance da normatividade; o discurso argumentativo, nesse sentido, para ser juridicamente relevante, terá que alcançar o que o próprio Castanheira Neves define como a normatividade da norma. Assim, resulta necessário tratar do modo como a racionalidade argumentativa traduz a normatividade e a compreensão dos fatos para, na sequência, estabelecer o alcance da tutela dos direitos, o que, do ponto de vista pragmático, exige esforço de fundamentação; em ambas as perspectivas, confronta-se a racionalidade argumentativa no direito com a verdade.

\subsection{Racionalidade argumentativa e a verdade dos fatos}

A construção do raciocínio jurídico argumentativo pressupõe uma ação comunicativa, o que confere relevância à questão da linguagem. Por outro lado, também não 
pode ser negligenciado o modo como a racionalidade argumentativa trata o problema da verdade dos fatos em termos de tutela de direitos.

$\mathrm{Na}$ racionalidade argumentativa, como de resto na vida em sociedade, a verdade e a linguagem estão interligadas; por isso, é necessário, em primeiro lugar, situar o papel da linguagem nos fundamentos do direito contemporâneo para, na sequência, tratar da relação entre racionalidade argumentativa e verdade.

Quando Ludwig Wittgenstein sustenta que o significado da palavra é o seu uso na fala (Die Bedeutung eines Wortes ist ein Gebrauch in de Sprache) fixa o caráter pragmático de compreensão das relações de vida em sociedade: a linguagem constitui uma forma de vida (2008, p. 31-61). Dessa afirmativa pode-se intuir o modo como a linguagem constitui uma forma de vida. A linguagem pode assumir uma feição científica que unifica a compreensão do mundo ou, como diz Jürgen Habermas, acerca da ideia de jogos de linguagem de Wittgenstein, o que está verdadeiramente em jogo, na relação entre linguagem e forma de vida, é o pluralismo de linguagens que interage na realidade, no quadro de concepção de mundo, de que resultam diversos mundos da vida (2009, p. 198); desde um jogo de linguagem não redutível ao uno é que se justifica a relação comunicativa que possa dar significado intersubjetivo à ação social; por isso, afirma Habermas que o comportamento de seguir uma regra inclui a intersubjetividade da validade de regras (2009, p. 202), exige uma posição compreensiva e hermenêutica e, consequentemente, um saber prático.

Uma outra questão emerge do problema do uso da linguagem na constituição de formas de vida que reside no fato de que a pluralidade de linguagens e de mundos da vida, embora contenha uma premissa democrática, pode não ser suficiente para explicitar o alcance da evolução social. Trata-se de perquirir o quanto a linguagem contribui para consolidar uma determinada forma de vida e, ao mesmo tempo, para imunizá-la dos desdobramentos e das necessidades de mudança no curso da evolução social. O uso na linguagem não incorpora apenas uma espécie de acordo em termos do que deva constituir forma de vida ou mundos da vida; ele também encerra desacordos, desdobramentos e conflitos que implicam alteração da forma de vida; a concepção mesma de forma de vida reclama uma concepção capaz de incorporar o modo como ela se altera em face dos conflitos que encerra. Assim, a pragmática do uso e da linguagem, que constitui uma forma de vida, deve estar aberta para o que Georges Didi-Huberman enxerga no pensamento de Aby Warbug de uma pragmática superior 
informada por um saber que se quer prático, mas também plástico, apoiado em lembranças e metamorfoses entrelaçadas (2013, p. 137-147); ou seja, a linguagem que constitui, transforma, modifica e revoluciona formas de vida.

Consequentemente, a compreensão da linguagem na constituição de formas de vida influencia a relação entre racionalidade argumentativa e verdade dos fatos; em torno dessa influência pode ser estabelecido o alcance da racionalidade argumentativa quando confrontada com o problema da verdade dos fatos.

O trânsito para uma racionalidade argumentativa, apoiada na linguagem, não significa que tenha, de fato, operada na realidade a passagem desde a postura científica da relação sujeito-objeto para uma relação sujeito-sujeito, segundo a proposta de uma virada linguística. A racionalidade argumentativa tanto pode incorporar elementos de uma compreensão positivista da realidade e dos fatos (nesse sentido regressiva, contaminada por um passado que se mantém), como também pode abrir espaço para uma visão antipositivista e crítica da realidade e da injustiça. Uma transformação na forma de compreensão do mundo, na direção de uma prática intersubjetiva de encontro com o outro, na dimensão sujeito-sujeito, pressupõe que a própria realidade possa assimilar essa postura, o que parece não ser o caso no momento em que ainda permanece a hegemonia do individualismo e de toda a forma de isolamento e preservação de interesses pessoais que lhe é característica, no quadro do modelo de economia neoliberal e das políticas de exceção.

Ao restringir-se à verdade dos fatos brutos, de cunho positivista, a racionalidade argumentativa pode incorporar ao direito uma prática de manutenção de formas de vida e de preservação de interesses e de titularidades; por outro lado, ao assimilar os fatos nos desdobramentos da materialidade da vida, pode abrir oportunidades para a mudança social e para a ampliação de titularidades de direitos.

O risco na atualidade da prática judiciária brasileira é o de que a racionalidade argumentativa se esgote na superficialidade de um suposto melhor argumento, incapaz de dar conta da compreensão da complexidade da realidade e dos fatos; tratar-se-ia, neste caso, de uma razão argumentativa que perdeu o compromisso com a verdade; o objetivo do argumento se reduz a persuadir, no sentido do que afirmam Hugo Mercier e Dan Sperber (2017), o que não significa, necessariamente, apoiar-se na verdade. Esse caráter reducionista do argumento 
pode revelar-se tanto mais real se o ensino jurídico no Brasil não for capaz de fornecer os elementos básicos indispensáveis para a compreensão do mundo, dos fatos e da relação dos fatos com a normatividade que confere sentido ao ordenamento jurídico.

\subsection{Fundamentação da decisão judicial e racionalidade argumentativa}

A racionalidade argumentativa desdobra efeitos na forma de fundamentação e de aplicação do direito e nos critérios de verdade que ela incorpora. Nos termos de uma teoria da argumentação, Klaus Günther sustenta que um dos principais problemas da sociedade, e consequentemente do direito, está relacionado a compatibilizar ação, norma e situação; para enfrentar esse problema ele propõe uma racionalidade discursiva de fundamentação e de aplicação, em que pressuposta a aceitação das razões dos participantes, ao mesmo tempo em que o discurso esteja organizado segundo modelos procedimentais e por um princípio de reciprocidade (2011).

A fundamentação da decisão judicial constitui desdobramento dos pressupostos de fundamentação e de aplicação no direito. A fundamentação da decisão judicial contempla dois pressupostos: o da procedimentalidade do discurso e o da assimilação das razões dos participantes; assim, o critério de verdade que a fundamentação da decisão judicial exige tem uma vertente procedimental e outra dialógica.

É necessário verificar então, de modo mais específico, como essas vertentes estão contempladas no ordenamento jurídico brasileiro, em especial no Código de Processo Civil de 2015, naquilo que se refere à fundamentação da decisão judicial, tomada neste momento como eixo específico para situar os efeitos práticos da racionalidade argumentativa.

Em termos principiológicos, observa-se no Código de Processo Civil brasileiro de 2015 uma guinada na direção de uma racionalidade argumentativa, de certo modo condizente com as premissas do Common Law e seu modelo de precedentes. Vive-se no Brasil, segundo Anderson Cortez Mendes, um momento de mutação entre o sistema do Civil Law e o do Common Law; em torno dessa mutação, diz ele, estrutura-se a figura do precedente que contempla um substrato fático de normatividade, de modo a assegurar estabilidade, ao mesmo tempo em que reforça a necessidade de fundamentação, nos termos do que determina o art. 489 do Código de Processo Civil; buscou-se estabelecer as razões da decisão e operacionalizar critérios de distinção (2015, p. 2-28). Essa racionalidade argumentativa se

CONPEDI LAW REVIEW | Braga - Portugal | v. 3 | n. 2 | p. 106 - 126 | JUL/DEZ. 2017 
estrutura no Código de Processo Civil brasileiro em dois eixos principais que são o contraditório e a fundamentação da decisão judicial. Na questão relativa ao contraditório, Nicola Picardi assinala que no processo judicial prevalece uma lógica orientada por técnicas argumentativas e justificativas; por essa lógica, o contraditório traduz investigação dialética, conduzida com a colaboração das partes, no âmbito do provável e do razoável, não do necessário e do inevitável; o contraditório, portanto, constitui instrumento de investigação da verdade provável (2008, p. 127-141). Na dialética que o contraditório implica no processo se desenvolve a construção da verdade que configura ou não o direito afirmado pela parte. Assim, a argumentação que está na essência do contraditório se volta para definir o que pode ser aceito como verdade provável ou razoável. A fundamentação da decisão judicial, por outro lado, também é informada pela argumentação. Enquanto Michele Taruffo sustenta que a qualificação dos fatos na fundamentação da decisão judicial trabalha em torno da verdade judicial (2006, p. 222-225), Jordi Ferrer Beltrán afirma que a aceitação de elementos probatórios suficientes para comprovar um fato observa uma premissa de verdade reconhecida válida no processo (2005, p. 35-38); Ricardo Luiz Lorenzetti, contudo, deixa claro que, por força dos paradigmas da teoria da argumentação, o processo trata da solução de problemas e não da averiguação da verdade (2009, p. 179).

A fundamentação da decisão judicial, observados os parâmetros de busca de solução de problemas, apoiada em uma racionalidade argumentativa, corre o risco de adotar um critério de verdade convencional, que pode não guardar relação com o que ocorreu na realidade. Esse risco se torna mais relevante se observado o que afirmam Francisco Cardozo Oliveira e Miguel Kfouri Neto no sentido de que, a partir do disposto no art. 489 do Código de Processo Civil brasileiro, a relação entre fatos e normas, na fundamentação da decisão judicial, adquire um caráter constitutivo (2015, p. 203-232). E esse caráter constitutivo, que repercute na configuração do direito afirmado pela parte, precisa desdobrar efeitos na realidade compatível com uma verossimilhança de verdade que possa ser empiricamente compreendida.

Assim, na relação entre racionalidade argumentativa e fundamentação da decisão judicial, o que possa ser verdadeiro se estrutura por uma procedimentalidade e por uma convenção em que pressuposto o risco de distanciamento das possibilidades de evidência 
empírica. O quanto isso possa contribuir para a justiça das decisões judiciais dependerá do compromisso do ensino jurídico com os pressupostos de garantias do Estado de Direito, e com os desdobramentos da normatividade na vida em sociedade.

\section{PROCESSO ELETRÔNICO, CULTURA DIGITAL E CONHECIMENTO JURÍDICO}

A Emenda Constitucional n. ${ }^{\circ} 45$ de 2004 introduziu na Constituição Brasileira de 1988 o princípio da razoável duração do processo, traduzido na esfera administrativa do Poder Judiciário pela incorporação de práticas de gestão e de desburocratização do processo. Os Juizados Especiais surgiram alinhados com a ideia de ampliar o acesso de pessoas pobres à justiça. Do ponto de vista estritamente administrativo, o Conselho Nacional de Justiça disciplinou práticas de gestão por metas, com o propósito de elevar a produtividade do Poder Judiciário. Facilitação de acesso e modelos de administração e gerência constituíram dois eixos de propostas de renovação da estrutura do Poder Judiciário no Brasil. O processo eletrônico se insere nessa dinâmica de assegurar maior eficiência na tramitação de processos.

A compreensão da função do processo eletrônico, contudo, em meio a uma racionalidade argumentativa que informa a aplicação do direito, engloba duas perspectivas de análise: aquela relacionada à intensificação do trabalho, na atual configuração da economia neoliberal, e a relacionada à cultura digital pós-moderna; ambas as perspectivas permitem relacionar o processo eletrônico com a questão do conhecimento jurídico, na medida em que as mídias digitais multiplicam acessos à informação e o trabalho constitui um saber-fazer que repercute na compreensão do direito.

\subsection{Processo eletrônico, intensificação do trabalho e redução da experiência}

O Tribunal de Justiça do Paraná, no Brasil, realizou estudo em 2012 que indicou que a introdução do processo eletrônico nas Turmas Recursais, integrantes do sistema de Juizados Especiais, reduziu em $48 \%$ o tempo de tramitação dos processos (2017). Este dado evidencia que a adoção do processo eletrônico opera a redução do tempo de tramitação dos processos e propicia economia de recursos e de espaço. Mas a redução do tempo de tramitação do processo não implica, necessariamente, redução de trabalho para juízes e funcionários; ele apenas modifica a lógica do trabalho, que passa de uma plataforma física para uma plataforma

CONPEDI LAW REVIEW | Braga - Portugal | v. 3 | n. 2 | p. 106 - 126 | JUL/DEZ. 2017 
digital. Nessa passagem, interagem formas de automação, de redução dos tempos mortos do processo e também formas de intensificação do trabalho. A redução do tempo do processo no meio digital se viabiliza mediante formas de intensificação do trabalho físico e intelectual de modo que o processo eletrônico também repercute efeitos na relação saber-fazer que caracteriza a aprendizagem no direito.

De acordo com Christophe Dejours, observou-se nas últimas décadas do Século XX que as atividades no trabalho, em que o trabalhador é obrigado a provar, em um tempo extremamente exíguo, seu espírito de iniciativa e de decisão para evitar consequências graves, contribui para acelerar formas de automação que reduzem o espaço do saber-fazer e da experiência; o conhecimento de normas e de procedimentos substitui a experiência; mas essa substituição não dispensa o engajamento subjetivo do trabalhador e o consequente sofrimento que isso acarreta (2011, p. 151-153).

Enquanto de um lado as tecnologias de automação comprimem o tempo de realização de tarefas, de outro, acelera-se a produtividade que, no ambiente informático-comunicativo, de acordo com Christian Marazzi, não se define mais pelo valor dos produtos acabados, mas pelo que ele denomina de cognitariado, espécie de trabalhadores que utilizam tecnologias mentais, simbólicas e comunicativas; o trabalho tende cada vez mais a se valer dos chamados recursos humanos intelectuais e consiste em mobilizar ideias e habilidades cognitivas (2009, p. 90-101). O serviço judiciário não escapa a essa prática porque está inserido na lógica que utiliza recursos humanos intelectuais, ideias e habilidades cognitivas.

O processo eletrônico incorpora essas duas dinâmicas de compressão do tempo de realização de tarefas e de mobilização de ideias e habilidades cognitivas concentradas, de modo a promover a intensificação do trabalho. Em torno do processo eletrônico não se estrutura uma redução do trabalho; o que se reduz é o número de trabalhadores, porque as tarefas são comprimidas, e intensificado o esforço cognitivo.

A repetição de tarefas automatizadas no ambiente eletrônico contribui para reduzir e redimensionar a experiência do saber-fazer que é elemento determinante na construção do conhecimento jurídico. Tomada a visão de Natalino Irti, o ambiente eletrônico do processo se alinha a um saber que ele define como saber técnico funcional de prestação, que refuta a relação entre sujeitos e exige a impessoalidade objetiva da prestação técnica; trata-se da 
linguagem fracionária que, segundo Natalino Irti, é requerida pela divisão do trabalho na lógica do capitalismo, ou seja, o domínio da tecno-economia que pressupõe uma saber técnico com uso aplicado (2004, p. 68-78).

À prática do processo eletrônico liga-se um saber jurídico fragmentado de que resulta uma relação específica entre saber e fazer que está na essência do aprendizado no direito. Uma vez considerado o que sustentam Alfredo Bullard e Ana C. Maclean, no sentido de que a aprendizagem no direito tem pelos menos duas dimensões, uma teórica e outra prática, que são indissociáveis (2003, p. 169-188), pode-se afirmar que o processo eletrônico introduz uma nova dinâmica na relação entre teoria e prática no conhecimento jurídico que tanto pode ampliar como reduzir horizontes na tutela de direitos. De todo modo, deve-se levar em conta que a dinâmica de compressão do tempo e de intensificação cognitiva, aliada à repetição de tarefas exigida pelo incremento de casos nos tribunais, contribui para esvaziar a experiência e o sentido envolvidos na tarefa de interpretação e de aplicação, com repercussão na tutela de direitos.

Por outro lado, não pode ser negligenciado o potencial de inovação que o processo eletrônico propicia, já que a plataforma digital permite incorporar novas perspectivas de valoração da prova e de compreensão dos fatos. Como diz Francisco Cardozo Oliveira, os meios digitais propiciam novos patamares de compreensão dos fatos e da realidade porque a racionalidade imagética penetra o sistema jurídico e pode influenciar a forma como articulada a tutela de direitos na sociedade de massas contemporânea (2008, p. 191-214). A imagem, contudo, não está isenta de dúvida dado que ela não esgota a representação da realidade, conforme já ficou evidenciado no campo da arte e da produção artística. Não chega a ser incomum nos tribunais brasileiros julgamentos em que a imagem mostra um determinado fato e os juízes chegam a conclusões diferentes acerca do alcance do direito em jogo; por exemplo, em um caso de atropelamento filmado por dispositivos de segurança a imagem pode incorporar vários ângulos que dificultam o estabelecimento da culpa e da responsabilidade patrimonial pela indenização.

O processo eletrônico, na condição de aparato tecnológico, introduz uma nova dinâmica de prática na cultura jurídica brasileira que pode ser útil para ampliar horizontes de tutelas de direito, com efeitos positivos para a aprendizagem jurídica; mas, ao mesmo tempo,

CONPEDI LAW REVIEW | Braga - Portugal | v. 3 | n. 2 | p. 106 - 126 | JUL/DEZ. 2017 
pode limitar o saber a superficialidade das imagens, no contexto de compressão do tempo, e reduzir-se a mero dispositivo de gestão administrativa do serviço judiciário.

\subsection{Paradoxos do conhecimento jurídico na cultura digital}

A relação entre saber e fazer que se configura no conhecimento jurídico a partir da introdução de aparatos digitais na prática judiciária, em especial na realidade brasileira, deriva do modo como articulada a cultura digital. Com efeito, na realidade pós-moderna, as mídias digitais representam novo impulso para a acumulação de capital e, para o que interessa nesta análise, para a ciência e o conhecimento tendo-se em conta, neste último caso, especificamente a ciência e o conhecimento jurídicos.

A prática jurídica propiciada pelo processo eletrônico, conforme já assinalado, tem potencial para influenciar o conhecimento teórico do direito, assim como o processo de aprendizagem. É preciso ter em conta, porém, os efeitos da cultura digital em relação ao conhecimento jurídico. Sobre essa questão convém desdobrar a análise em dois momentos; um mais geral, voltado para a configuração da cultura digital propriamente dita, e outro, mais específico, sobre os desdobramentos dessa cultura no conhecimento jurídico, e os paradoxos que disso deriva.

As mídias digitais propiciam novas perspectivas teóricas; no campo do direito a tecnologia digital está confrontada com exigências de renovação na regulação jurídica de titularidades e com a possibilidade de novas perspectivas de trabalho criativo e de superação de limites nos fundamentos da ciência jurídica. A tecnologia digital se estrutura mediante captura de ideias e de sistemas de informação e exige interação e atuação em rede; altera-se o modo de aprendizagem e de produção do conhecimento. Na produção artística, por exemplo, conforme enfatiza Louise Poissant, opera-se a interatividade dialógica em que o conteúdo permanece aberto aos acréscimos de funcionalidades e de sentido (2009, p. 71-90); a compreensão do sentido da obra de arte exige interpretação demarcada pelo discurso e pela presença do outro, ou seja, ganha relevo uma racionalidade hermenêutica, a exemplo do que ocorre com o direito.

CONPEDI LAW REVIEW | Braga - Portugal | v. 3 | n. 2 | p. 106 - 126 | JUL/DEZ. 2017 
A produção de conhecimento no direito, em face das novas potencialidades das mídias digitais, coloca a necessidade de assimilar a racionalidade imagética no processo de aprendizagem, de forma a potencializar a criatividade e as ferramentas disponíveis para a solução de conflitos nos tribunais. Essa tarefa, contudo, não se limita a introduzir ferramentas digitais nas relações de ensino-aprendizagem; ela se refere a uma questão mais profunda de compreensão da estrutura da racionalidade digital e o que dela pode ser extraído para o conhecimento jurídico. Assim, em termos metodológicos, pode revelar-se útil a proposta de Peter Lunenfeld, baseada nos pressupostos da dialética negativa de Theodor W. Adorno, de adoção de uma dialética digital, no sentido de considerar que o modo binário cibernético “ 0 ” e “1" ou "off” e “on" não conduz a dualidade entre tese e antítese a uma síntese, mas a uma permanente abertura para o novo e para a possibilidade de constante regeneração do sistema, avessa a metanarrativas (1999, p. XVIII). A dialética digital, conforme anota Michael Heim, poderia ser complementada pela racionalidade argumentativa ou pelo modelo do diálogo (1999, p. 38-41). De um modo ou de outro, a racionalidade digital não deixa de estar integrada à tradição do pensamento dialético e da filosofia hegeliana.

Considerado que a tecnologia digital inviabilizou a síntese e o idêntico do conceito, então o conhecimento jurídico está fadado a enfrentar a crítica e as necessidades de mudança exigidas pela evolução social.

A radicalidade dialética propiciada pela cultura digital enfrenta um paradoxo com efeitos no conhecimento jurídico; de um lado, ela pode limitar o conhecimento e fazer surgir uma nova forma de ignorância, o daqueles alijados da cultura imagética; de outro, pode propiciar novas possibilidades criativas e potencializar o conhecimento. Na primeira direção, Vilém Flusser adverte para o fato de que o conhecimento humano se construiu por meio de linhas escritas e que, recentemente, a tecnologia digital, produziu nova articulação de representação do mundo mediante imagens em movimento, em que o tempo histórico linear das linhas escritas foi elevado ao nível da superfície das imagens; essa mudança, segundo ele, coloca duas situações: enquanto uma elite intelectualizada continua a compreender o mundo de forma abstrata, por meio de conceitos, na esteira da cultura da escrita, as massas se valem das imagens como forma de conhecimento, com a agravante de perder a experiência original do mundo; em ambas as situações perde-se o sentido de compreensão da realidade (200, p. 104-120). Vilém Flusser não deixa de ressaltar que é possível escapar dessa armadilha desde 
que compreendido o caráter inovador das mídias digitais, de modo que a racionalidade imagética consiga incorporar a racionalidade conceitual. Em relação a essa segunda direção, convém anotar que Boris Groys sustenta que a Internet instaurou uma nova relação entre a natureza e a técnica desdobrada na relação, agora incerta, entre cópia e original; não é mais possível garantir a identidade entre original e cópia a partir de imagens digitais, na medida em que cada visualização exige uma interpretação específica do usuário (2014, p. 193-203); nesse contexto, diz ele, a Internet permite operar descontextualizações e recontextualizações e ainda fortalece o potencial utópico do novo (2016, p.195-213).

Um traço comparativo entre as ideias de Vilém Flusser e de Boris Groys permite sustentar que a cultura digital contempla um paradoxo na medida em que tanto pode assimilar a criatividade e o novo e, com isso, ampliar o conhecimento, como pode também reduzir o potencial de compreensão do mundo. A aprendizagem do direito não está imune a esse paradoxo, máxime se considerado que o conhecimento juridico evoluiu por meio da escrita e ainda não é certo, pelo menos na realidade brasileira, que o processo eletrônico tenha propiciado a convergência do pensamento conceitual e do pensamento imagético e seja capaz de articular uma prática de descontextualizações e recontextualizações, de acordo com as exigências de mudança da sociedade brasileira.

\section{O TEMPO DA APRENDIZAGEM E DA JUSTIÇA E A ACELERAÇÃO DA VIDA NA PÓS-MODERNIDADE}

As práticas de ensino-aprendizagem do direito, assim como a articulação entre interpretação e aplicação exigida para a realização da justiça no mundo, estão determinadas pelo registro da temporalidade. De certo modo, existe uma complementaridade funcional entre o tempo do ensino-aprendizagem e o tempo de realização da justiça dado o pressuposto de uma racionalidade hermenêutica que confere sentido aos fundamentos do direito; a racionalidade argumentativa interfere em ambas as temporalidades; o modo como essa interferência se opera considera os processos de aceleração que desde a modernidade caracterizam a vida em sociedade. Harmut Rosa procura desenvolver uma teoria crítica da temporalidade na pós-modernidade enfatizando que a modernidade se caracteriza por 
processos de aceleração social: fazer mais coisas em menos tempo; a aceleração da vida, diz ele, decorre da competitividade instaurada pelo modelo de economia capitalista; segundo Harmut Rosa, a educação devia funcionar como um elemento de estabilização dos processos de aceleração da vida; contudo, não é o que o ocorre na pós-modernidade em face das exigências de flexibilização, cujos reflexos, em termos de produção científica, resultam no poder de convicção do melhor argumento, em torno da febre de publicações, sem força para questionar fundamentos (2016, p.91-96). Não seria demasiado afirmar que a racionalidade argumentativa transita da prática para a teoria no direito. Assim, a análise dos efeitos do tempo e dos processos de aceleração nas práticas de ensino-aprendizagem no direito pode ser desdobrada em dois momentos: o que trata da questão da velocidade do tempo da justiça e da aprendizagem do direito na modernidade e o que se refere à aceleração da temporalidade da justiça e da aprendizagem do direito na realidade pós-moderna.

\subsection{As velocidades do tempo da justiça e da aprendizagem na modernidade e seus efeitos na vida das pessoas e dos direitos}

A aprendizagem compreende um processo que percorre a vida da pessoa ao longo do tempo; esse processo se inicia antes mesmo da entrada da pessoa na escola; as práticas de socialização na família e na comunidade constituem formas de aprendizagem, cujos efeitos se produzem ao longo do processo de escolarização e até na vida profissional. Pierre Bourdieu ilustra essa questão com as ideias de capital social e capital cultural; o capital social, diz ele, se define pelo conjunto de recursos atuais e potenciais ligados a rede de relações institucionais vinculadas a um grupo de pessoas; esses recursos não se resumem a relações de proximidades ou de condições sociais e econômicas; eles assumem um caráter simbólico do reconhecimento da situação da pessoa em sociedade. Já o capital cultural está relacionado ao problema da desigualdade e sua influência no desempenho escolar de pessoas provenientes de diferentes classes sociais; o capital cultural, de acordo com Pierre Bourdieu, pressupõe um processo de acumulação e de assimilação da cultura, um ter que se tornou ser, uma propriedade que passa a integrar a pessoa; o capital cultural também pressupõe a apropriação simbólica de produtos culturais e uma forma institucionalizada de competência cultural objetivada no diploma (2013, p. 73-88).

CONPEDI LAW REVIEW | Braga - Portugal | v. 3 | n. 2 | p. 106 - 126 | JUL/DEZ. 2017 
O sucesso da aprendizagem, portanto, pressupõe um conjunto simbólico de valores sociais e culturais que se integram à personalidade da pessoa na trajetória da vida. Em torno do processo de ensino-aprendizagem se estrutura uma temporalidade de assimilação e consolidação de cultura e de conhecimento; nessa temporalidade está pressuposta uma experiência de vida, já que na modernidade, a educação se manteve atrelada aos objetivos de assegurar autonomia e emancipação. A própria ideia de experiência confronta com as possibilidades de conhecimento. Lembrando Reinhart Koselleck, quando ele define experiência faz alusão a que nela se fundem tanto a elaboração racional quanto formas inconscientes de comportamento, que não precisam mais estar presentes no conhecimento; é desse modo que a experiência que a pessoa incorpora passa a ser transmitida por gerações e instituições; a história então passa a ser concebida como conhecimento de experiências alheias (2006, p.304-309). A experiência que se incorpora à vida da pessoa contribui para a apropriação de capital social e de capital cultural e permite a ela agir em sociedade. Francisco Mora enfatiza que o processo de aprendizagem assimila necessidades emocionais que despertam a atenção para o conhecimento (2017); sobre essa questão, Roberto Lent fala do desenvolvimento de competências socioemocionais (2017, p. 30-35). O processo de aprendizagem também contempla uma experiência na dimensão do envolvimento emocional. Mas a experiência se conforma no tempo, como diz Reinhart Koselleck, no tempo do passado atual, em que se operou a incorporação do conhecimento; contraposta a ideia de expectativa, ao longo da modernidade, a experiência perde espaço porque o futuro, ligado a noção de progresso, se desvincula do que veio a ser acumulado e cobra sempre mais a transformação constante em busca do novo (2006, p. 309-314).

A temporalidade do conhecimento que se acumula pela experiência se confronta na modernidade com esse processo de aceleração em direção ao futuro, que coloca limites para as possibilidades de emancipação e de autonomia da pessoa entendidas como a possibilidade de um agir determinado pela própria vontade.

Também o tempo da justiça se acelera na modernidade. Enquanto no direito privado o processo de acumulação de capital exige velocidade e dinamismo na conformação dos institutos jurídicos, de modo a assegurar as trocas no mercado, no direito penal a velocidade se distribui no modo de infligir punição aos desviados e contestadores da ordem do capital.

CONPEDI LAW REVIEW | Braga - Portugal | v. 3 | n. 2 | p. 106 - 126 | JUL/DEZ. 2017 
Incorpora-se ao ordenamento jurídico, na verdade, uma distribuição de velocidades; rapidez na tutela dos interesses financeiros e econômicos e lentidão na tutela dos interesses de lesões e de desrespeito de direitos daqueles atingidos pelas turbulências das dinâmicas de acumulação de capital.

O tempo da justiça na modernidade observa um paradoxo; os direitos humanos e de preservação da pessoa, por exemplo, dependem do tempo de articulação de lutas em face do sofrimento e da privação, enquanto os interesses financeiros e econômicos dispõem de instrumentos jurídicos para conferir velocidade e rapidez na tutela de direitos. De um modo ou de outro, a ordem jurídica não consegue se desvencilhar das exigências desse paradoxo, porque não dispõe de mecanismos para acelerar a tutela de direitos humanos e, ao mesmo tempo, retardar a satisfação de interesses voltados para o aumento de lucros.

Revela-se na modernidade uma conexão entre as temporalidades da aprendizagem do direito e a da justiça; enquanto se reduzem as possibilidades da experiência que permitem incorporar conhecimentos, em meio a uma realidade dominada por expectativas de futuros engendrados pela lógica de acumulação de capital, onde o processo de ensino-aprendizagem no direito se limita a fornecer habilidades profissionais e de competência, a realização da justiça resulta paralisada pela dupla exigência de tutela imediata de interesses financeiros e econômicos e de adiamento da tutela de direitos e de titularidades de pessoas. A racionalidade argumentativa surge como possibilidade de saída para esse impasse, mediante uma economia de argumentos em torno de interesses em conflito, em que o fundamento dialógico constitui a última instância de manutenção dos pressupostos do Estado de Direito.

\subsection{A aceleração da temporalidade da justiça e da aprendizagem na realidade pós- moderna}

$\mathrm{Na}$ tese IX sobre o conceito de história, um dos seus textos mais citados, Walter Benjamin demarca o movimento da temporalidade que se acelera na modernidade; na imagem do Angelus Novus de Paul Klee ele vê o anjo da história; enquanto o passado amontoa escombros sem cessar e, em face dele, não é mais possível demorar-se, despertar os mortos e juntar os destroços, uma tempestividade, que é o progresso, impele para o futuro. A modernidade se configura para Walter Benjamin como impossibilidade da experiência e como

CONPEDI LAW REVIEW | Braga - Portugal | v. 3 | n. 2 | p. 106 - 126 | JUL/DEZ. 2017 
urgência de afirmação do futuro; nessa passagem se manifesta uma urgência de salvação em que, todavia, espreita a catástrofe, o risco e a miséria.

A configuração da pós-modernidade vem na esteira da aceleração da temporalidade; como diz Zygmut Bauman, a pós-modernidade se caracteriza pela fluidez, a leveza, a mobilidade e a inconstância; mas ele ressalva que a fluidez não se prende no tempo e reforça a necessidade de mudança constante em que, paradoxalmente, o fluxo torna o significado irrelevante (2001, p. 7-22). Na pós-modernidade é necessário compreender o fluxo e as formas de interação em rede. De volta a Boris Groys, ele assinala que compreender a totalidade, do ponto de vista material, significa compreender a totalidade do fluxo, o que implica renunciar a toda espécie de metafísica; desse modo, diz ele, a revolução também é uma forma de aceleração: acelerar artificialmente o fluxo do mundo (2016, p. 9-31); o que importa, na verdade, é intensificar formas de aceleração. Assim, se a pós-modernidade é fluxo que reduz as possibilidades de significado, por outro lado, compreender os fluxos que ela engendra pode permitir aberturas na dinâmica de aceleração do tempo na direção da justiça e da emancipação.

Nesse contexto, a relação entre ensino-aprendizagem e justiça precisa confrontar a encruzilhada entre permanecer atrelada a superficialidade das imagens e seus desdobramentos em termos de conhecimento fragmentado pelo excesso de informações ou abrir oportunidades para o conhecimento da totalidade do fluxo e as chances de resgate da criatividade e da inovação.

Vista a questão nessa perspectiva, o ensino nas universidades ocidentais parece caminhar na direção de consolidar uma prática de ensino aprendizagem comprometida com o desenvolvimento de competências, com objetivo de empregabilidade e de inovação de produtos para os mercados. Na União Europeia, a partir da estratégia de Lisboa de 2000, a produção de conhecimento passou a orientar-se segundo as demandas dos mercados por inovação tecnológica e pelo paradigma da competitividade nas atividades de pesquisa. Essa proposta, segundo Isabelle Bruno, Pierre Clément e Christian Laval, formula uma concepção de ensino-aprendizagem voltada para habilitar a pessoa para trabalhos cognitivos e de responsabilidade pelo aprendizado durante a vida profissional (2010, p. 36 e 37).

CONPEDI LAW REVIEW | Braga - Portugal | v. 3 | n. 2 | p. 106 - 126 | JUL/DEZ. 2017 
Em relação ao ensino-aprendizagem no direito, essa mudança de orientação reduz o compromisso da universidade com a formação da pessoa; a aprendizagem no direito, inserida na dinâmica de aceleração da temporalidade que caracteriza a pós-modernidade, se resume ao domínio de técnicas e de habilidades profissionais. Assim, a racionalidade argumentativa opera para encurtar o tempo de compreensão do sentido da normatividade, em busca do favorecimento do melhor argumento, que quase sempre surge do lado dos interesses financeiros e econômicos. Na realidade brasileira, essa situação conduz ao aumento de desigualdades e assimetrias e resulta em violência e sofrimento.

Surge nítida a relação entre a aceleração da temporalidade nas práticas de ensinoaprendizagem no direito e a justiça, que se opera por meio da racionalidade argumentativa: enquanto a razão argumentativa se define pelo melhor argumento, a justiça se reduz a um jogo de rituais esvaziados característico dos tempos de decadência.

\section{CONCLUSÃO}

Colocou-se como problema a indagação acerca do modo como o tempo de aprendizagem e o da justiça podem ser influenciados pela razão argumentativa e pelo processo eletrônico, observado o contexto da pós-modernidade e de evolução da sociedade brasileira.

A análise se desenvolveu a partir da compreensão de que a racionalidade argumentativa, apoiada em pressupostos de verdade convencional, corre o risco de esgotar-se na superficialidade do melhor argumento, incapaz de alcançar a complexidade da realidade e dos fatos, com prejuízos para a efetividade da tutela de direitos.

Também ficou evidenciado na análise que o processo eletrônico e a cultura digital que lhe é subjacente, embora contribuam para a redução do tempo do processo, carregam um paradoxo; de um lado a possibilidade de ampliação da criatividade; de outro, a redução da compreensão do mundo.

Mas a compreensão dos efeitos da racionalidade argumentativa, no contexto da cultura digital e do processo eletrônico, somente ganha sentido em face de uma análise da temporalidade do processo de aprendizagem e da justiça, mediada pela concepção de aceleração da vida que se intensifica na passagem entre modernidade e pós-modernidade. 
A razão argumentativa parece buscar uma saída para o impasse decorrente da redução da experiência e das possibilidades de conhecimento, e das limitações de realização da justiça, em função de velocidades diferenciadas da tutela de interesses financeiros e econômicos e das tutelas de direitos e de salvaguarda da pessoa.

Em termos de síntese conclusiva, a análise indica que a racionalidade argumentativa funciona para comprimir a temporalidade de compreensão do sentido da normatividade, mediante a premissa do melhor argumento que, por sua vez, reduz a justiça a um jogo de rituais vazios. Do ponto de vista da aprendizagem no direito e da prática de aplicação, a racionalidade argumentativa repete o arcaico com verniz novidadeiro: ignorar desigualdades e assimetrias, na evolução da sociedade brasileira, e preservar direitos e titularidades consolidados, agora no contexto de aumento da selvageria entre incluídos e excluídos. Tratase, como sempre, de um conhecimento jurídico e de uma justiça reduzidos ao mínimo necessário para a estabilização das crises recorrentes da economia brasileira.

\section{REFERÊNCIAS}

BAUMAN, Zygmunt. Modernidade líquida. Rio de Janeiro: Jorge Zahar Editor, 2001. BELTRAN, Jordi Ferrer. Prueba y verdad en el derecho. Madrid: Marcial Pons, 2005. BOURDIEU, Pierre. Escritos de educação. 14. a ed. Petrópolis: Editora Vozes, 2013. BRUNO, Isabelle; CLÉMENT, Pierre; LAVAL, Christian. La grande mutation néolibéralisme et éducation en Europe. Paris: Éditons Sullepse, 2010.

BULLARD, Alfredo. MACLEAN, Ana C. La enseñanza del derecho: cofradia o archicofradia. EI derecho como objeto e instrumento de transformación. Seminario en Latinoamérica de Teoría Constitucional y Política. Buenos Aires: Editores del Puerto, 2003, p. 169-188.

DEJOURS, Christophe. Da psicopatología à psicodinâmica do trabalho. 3. a ed., Rio de Janeiro: Editora Fiocruz, 2011.

DIDI-HUBERMAN, Georges. A imagem sobrevivente - história da arte e tempo dos fantasmas segundo Aby Warburg. Rio de Janeiro, Editora Contraponto, 2013.

FLUSSER, Vilém. O mundo codificado. São Paulo: Editora Cosac Naify, 2007.

CONPEDI LAW REVIEW | Braga - Portugal | v. 3 | n. 2 | p. 106 - 126 | JUL/DEZ. 2017 
GROYS, Boris. Volverse publico - las transformaciones del arte en el ágora contemporánea. Buenos Aires: Caja Negra Editora, 2014.

Arte en flujo - ensayos sobre la evanescencia del presente. Buenos Aires:

Caja Negra Editora, 2016.

GUNTHER, Klaus. Teoria da argumentação no direito e na moral. Justificação e aplicação. Rio de Janeiro: Editora Forense, 2011.

HABERMAS, Jurgen. A lógica das ciências sociais. Petrópolis: Editora Vozes, 2009.

HEIM, Michael. The cyberspace dialectic. in The Digital Dialetic, Cambridge: MIT Press, 1999, p. 24-45.

IRTI, Natalino. Nichilismo giuridico. Bari: Editori Laterza, 2004.

KOSELLECK, Reinhart. Futuro passado - contribuição à semântica dos tempos históricos.

Rio de Janeiro: Editora Contraponto/Editora Puc-Rio, 2006.

LENT, Roberto. Especialista em conexões. ZORZETTO, Ricardo (Entrevistador). Revista

Pesquisa Fapesp. São Paulo, maio de 2017, ano 18, n. ${ }^{\circ}$ 255, p. 30-35.

LORENZETTI, Ricardo Luiz. Teoria da decisão judicial - fundamentos de direito. São Paulo, Editora Revista dos Tribunais, 2009.

LUNENFELD, Peter. Screen grabs: the digital dialectic and new media theory. in The Digital Dialetic. Cambridge: MIT Press, 1999, p. XV-XXI.

MARAZZI, Christian. O lugar das meias - a virada linguística da economia e seus efeitos sobre a política. Rio de Janeiro: Editora Civilização Brasileira, 2009.

MENDES, Anderson Cortez. Dever de fundamentação no novo Código de Processo Civil e os precedentes vinculares. Revista Eletrônica de Direito Processual Civil. Rio de Janeiro. Pósgraduação em direito da UERJ, vol. 16, julho-dezembro de 2015, p. 2-28.

MERCIER, Hugo; SPERBER, Dan. The enigma of reason. Cambridge, Massachusetts: Harvard University Press, 2017.

MORA, Francisco. Neuroeducación - solo se puede aprender aquello que se ama. Madrid, Alianza Editorial, 2017.

NEVES, A. Castanheira. Metodologia jurídica - problemas fundamentais, Coimbra: Coimbra Editora, Universidade de Coimbra, 1993.

OLIVEIRA, Francisco Cardozo. KFOURI NETO, Miguel. O alcance da fundamentação da decisão judicial na relação entre fatos e normas segundo o inciso I do $§ 1 .^{\circ}$ do artigo 489 do

CONPEDI LAW REVIEW | Braga - Portugal | v. 3 | n. 2 | p. 106 - 126 | JUL/DEZ. 2017 
novo Código de Processo Civil. In VASCONCELlOS, Fernando Andreoni; ALBERTO, Tiago Gagliano Pinto (Org.). O dever de fundamentação no novo CPC - análises em torno do art. 489. Rio de Janeiro: Editora Lumun Juris, 2015, p. 203-232.

OLIVEIRA, Francisco Cardozo. Os limites da linguagem no processo: o sistema mídia e o sistema jurídico. In GUNTHER, Luiz Eduardo (Coord.). Jurisdição - crise, efetividade e plenitude institucional. Curitiba: Juruá Editora, 2008, p. 191-214.

PICARDI, Nicola. Jurisdição e processo. Rio de Janeiro: Editora Forense, 2008.

POISSANT, Louise. A passagem do material para a interface. In Arte, ciência e tecnologia passado, presente e desafios. São Paulo: Editora Unesp, 2009.

ROSA, Harmut. Alienación y aceleración - Hacia una teoría crítica de la temporalidad en la modernidad tardía. Buenos Aires: Katz Editores, 2016.

TARUFFO, Michele. La motivación de la sentencia civil. México: Tribunal Electoral del Poder Judicial de la Federación, 2006.

TRIBUNAL DE JUSTIÇA DO PARANA. https://www.tjpr.jus.br/destaques//asset_publisher/11KI/content/projudi-completa-10-anos-com-mais-de-8-milhoes-deprocessos-eletronicos cadastrados/18319? Acesso em 18.05.2017.

WITTGENSTEIN, Ludwig. Investigaciones filosóficas. Barcelona: Editorial Critica, 2008. 